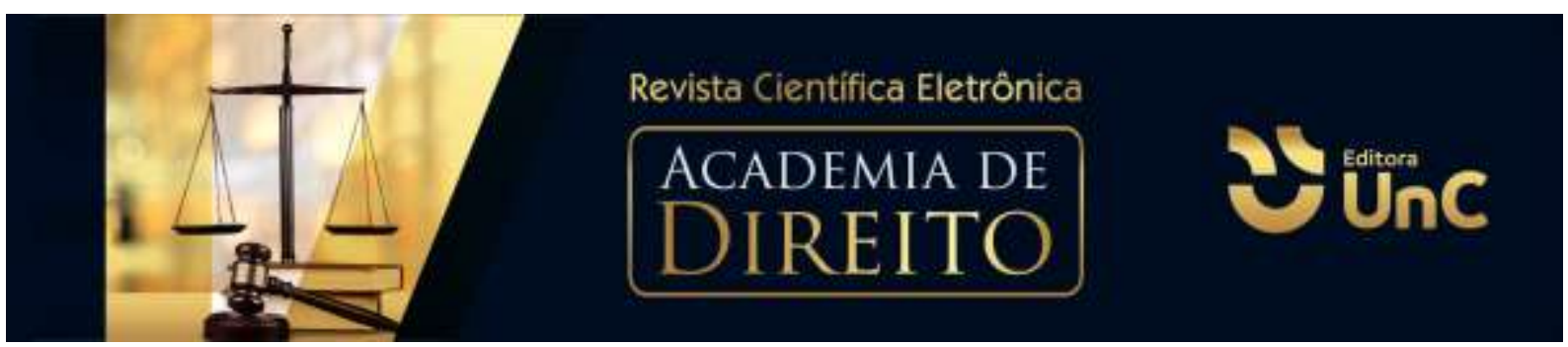

\title{
EFETIVIDADE DOS MEIOS ATÍPICOS NO PROCESSO DE EXECUÇÃO POR QUANTIA CERTA A LUZ DO ARTIGO 139, IV DO CPC
}

\section{EFFECTIVENESS OF ATYPICAL MEANS IN THE PROCESS OF EXECUTION OF PAYING RIGHT AMOUNT IN THE LIGHT OF ARTICLE 139, IV OF THE CPC}

\author{
Jorge Antonio Magri ${ }^{1}$
}

Morgana Henicka Galio ${ }^{2}$

\begin{abstract}
RESUMO
O presente trabalho concentra-se na área do direito processual civil, especificamente acerca da execução por quantia certa e tem como objetivo principal, problematizar a efetividade dos meios atípicos no processo de execução, que possui salvaguarda legal o Artigo 139, IV, do CPC de 2015. Este dispositivo legal confere ao juiz poderes discricionários para a concretização do direito do jurisdicionado, todavia sempre buscando manter um equilíbrio para que o processo de execução não venha ferir direitos e garantias fundamentais que impeça os executados de garantirem uma existência digna, fazendo com que o processo de execução se torne mais justo e efetivo, onde, notadamente a busca pelo equilíbrio e efetividade da execução será objeto deste estudo. Em relação à metodologia empregada na pesquisa, utilizou-se método dedutivo e técnicas de pesquisa bibliográfica e documental, posto que, constrói-se a partir de obras doutrinárias, jurisprudências e artigos científicos, além de instrumentos legais diversos, como a Constituição Federal de 1988, o Código Civil, Código de Processo Civil, com o viés primordialmente qualitativo. Ao final, constatase que as medidas atípicas no processo de execução por quantia certa são um aparato jurídico necessário para dar mais efetividade ao processo de execução, e como consequência tornando a fase executiva mais justa.
\end{abstract}

Palavras-Chave: Efetividade. Medidas executivas atípicas. Execução por Quantia Certa.

\footnotetext{
${ }^{1}$ Acadêmico do curso de Direito da Universidade do Contestado. Campus Concórdia. Santa Catarina. Brasil. E-mail: jorgemagri45@gmail.com

${ }^{2}$ Mestre em Direito pela Universidade Federal de Santa Catarina - UFSC, Membro do Instituto Brasileiro de Direito Processual - IBDP, professora no curso de Direito da Universidade do Contestado - Campus Concórdia. Santa Catarina. Brasil. E-mail: morgana.galio@unc.br
} 


\begin{abstract}
The present work is concentrated in the area of civil procedure, specially about execution for a certain amount and this study has as main objective, to question the effectiveness of atypical means in the execution process, which Article 139, IV, of the CPC 2015 is legally safeguarded. This legal provision gives the judge discretionary powers for the realization of the jurisdiction's right, however always seeking to maintain a balance so that the enforcement process does not harm fundamental rights and guarantees that prevent those executed from guaranteeing a dignified existence, making the execution process more fair and effective, where, notably the search for balance and effectiveness of execution will be the object of this study. Regarding the methodology used in the research, the method used was deductive and bibliographic and documentary research techniques, since, it uses doctrines, jurisprudence and scientific articles, in addition to diverse legal instruments, such as 1988 Federal Constitution, the Civil Code, Code of Civil Procedure, with a primarily qualitative bias. At the end, it appears that the atypical measures in the execution process for a certain amount is a necessary legal apparatus to give more effectiveness to the execution process, and as a consequence making the executive phase more just.
\end{abstract}

Keywords: Effectiveness. Atypical means. Execution for a certain amount.

\title{
1 INTRODUÇÃO
}

Com o advento do CPC/2015, tornou-se imprescindível a discussão a respeito do artigo 139, IV, que confere ao juiz poderes executivos discricionários para a concretização do direito do jurisdicionado. Todavia, é necessário manter o equilíbrio para que o procedimento executivo não viole direitos e garantias fundamentais que impeça os executados de garantirem uma existência digna. Isto faz com que o processo de execução se torne mais justo e efetivo, notadamente, o funcionamento desta busca pelo equilíbrio e efetividade da execução será objeto deste estudo.

Neste contexto, surge o seguinte questionamento: Há efetividade na utilização de medidas executivas atípicas no processo de execução por quantia certa?

Para responder o referido questionamento, primeiramente será realizada uma breve contextualização histórica sobre a evolução legislativa relacionada ao tema da atipicidade dos meios de execução no processo civil brasileiro, elencando ainda as formas de execução, sua natureza jurídica e o choque de princípios ao se adotar esta forma atípica de execução. Por fim, será realizada análise com base nos estudos a fim de verificar a efetividade destas medidas no processo de execução.

Ressalta-se que o presente artigo tem como objetivos analisar a forma como se dá o processo de execução por quantia certa no direito processual civil brasileiro, 
e suas respectivas mudanças ao longo do tempo, com ênfase nas medidas executivas utilizadas no processo. Busca verificar as principais medidas executivas autorizadas em lei, que são utilizadas para tentar satisfazer a tutela jurisdicional do interessado, e ao final verificar a real efetividade das medidas atípicas dentro do ordenamento jurídico.

Este trabalho é pautado por uma metodologia exploratória, com abordagem qualitativa e utiliza método dedutivo. O procedimento bibliográfico e documental foi utilizado, analisando legislação, doutrina, jurisprudência, revistas e artigos científicos.

\section{PROCESSO DE EXECUÇÃO POR QUANTIA CERTA}

De início, para compreender melhor a utilização de medidas atípicas no processo de execução, antes é necessário estudar sobre o processo executivo e as formas de execução existentes no ordenamento processual civil brasileiro.

Executar consiste em "satisfazer uma prestação devida", destarte, a execução ocorre de maneira forçada, quando o cumprimento da prestação é obtido a partir de atos executivos praticados pelo Estado (DIDIER JUNIOR et al, 2017, p. 45). Portanto, o processo de execução busca "a satisfação da prestação a que tem direito o credor", enquanto no processo de conhecimento o juiz determina a aplicação de uma regra jurídica ao caso, no processo de execução o objetivo é efetivar o conteúdo daquela regra já estabelecida título executivo (THEODORO JUNIOR, 2017, p. 295).

A pretensão executiva tem como requisito a existência de título executivo, conforme art. 783 do CPC: "A execução para cobrança de crédito fundar-se-á sempre em título de obrigação certa, líquida e exigível” (BRASIL, 2015).

Ademais, a obrigação consubstanciada no título executivo deve ser certa, líquida e exigível. Obrigação certa é aquela da qual, a partir do título, se tem certeza da existência; é líquida quando determinada quanto ao seu objeto; e é exigível quando pode ser imediatamente imposta (MARINONI; ARENHARDT; MITIDIERO, 2017). Assim, é possível afirmar que o título executivo é o instituto processual de grande importância, pois é ele que autoriza a execução, define seu objeto e os limites da jurisdição executiva (SCARPARO, 2018).

Estando diante de uma prestação de pagar quantia certa, devem ser utilizadas técnicas processuais executivas que culminam com a expropriação forçada do 

CPC

patrimônio do devedor em favor do credor até o limite necessário à satisfação do crédito. Neste sentido, o que se verifica é a transferência de patrimônio do devedor para o credor no limite do crédito exequendo (RODRIGUES, 2015).

Ademais, a execução pode ser classificada como mediata ou imediata, conforme a espécie de título executivo. Execução mediata é aquela fundada em um título executivo extrajudicial, de modo que não é necessária uma ação de conhecimento para que seja reconhecido o direito do autor. O título extrajudicial contém uma obrigação imposta ao devedor, se a obrigação for cumprida voluntariamente, não haverá processo de execução, contudo, se não adimplida a obrigação pelo devedor, dar-se-á início ao processo de execução para que seja cumprida pelo devedor a obrigação contida no título (GONÇALVES, 2019). Para pleitear o cumprimento da obrigação estabelecida em um título executivo extrajudicial será necessário instaurar um processo autônomo de execução (RODRIGUES, 2015).

Por sua vez, a execução imediata é fundada em título judicial, oriundo de um processo de conhecimento, em que uma parte ingressa contra a outra apresentando fatos, provas e fundamentos legais e ao final do processo é estabelecida a obrigação por meio de uma sentença. Caso está não seja cumprida voluntariamente pela parte contrária, se desencadeará a fase executiva do processo, fundada em título judicial (GONÇALVES, 2019). Este procedimento é denominado cumprimento de sentença (RODRIGUES, 2015).

Portanto, o procedimento executivo a ser adotado dependerá do título. Tratando-se de título judicial, aplicam-se as regras do cumprimento da sentença dispostas nos artigos 513 a 538 do CPC. Sendo extrajudicial, a execução segue as normas contidas a partir do art. 771 do CPC (DIDIER JUNIOR et al, 2017).

Insta observar que apesar das distinções entre o procedimento do cumprimento de sentença e do processo autônomo de execução, tratando-se de obrigação de pagar quantia certa, ambos são pautados pela utilização de medidas executivas, a fim de alcançar a satisfação da prestação devida. 


\title{
2.1 MEDIDAS EXECUTIVAS
}

Como se sabe o procedimento executivo é o instrumento para satisfazer a tutela jurisdicional do interessado, e para tanto, se utiliza do cumprimento de sentença e do processo de execução.

Para satisfazer à pretensão do exequente, destacam-se os atos processuais executivos, aqueles que dão característica e tipicidade à função executiva. Esses atos processuais executivos são as denominadas medidas executivas e são realizados mediante as técnicas processuais de sub-rogação ou coercitivas (RODRIGUES, 2015).

Até onde se tem registro, as primeiras medidas executivas criadas pela humanidade surgiram no direito romano, com a criação da lei das XII tábuas, como explica José Carlos Moreira Alves:

\begin{abstract}
A execução da sentença não cumprida pelo réu se fazia contra a sua própria pessoa ou contra seus bens. O autor solicitava do magistrado a concessão, ao mesmo tempo, das duas espécies, ou, então, apenas de uma delas (o que ocorria, necessariamente, nos casos em que não era possível proceder-se à execução sobre a pessoa do devedor, por haver este, por exemplo, morrido). A execução sobre a pessoa do réu (que era a única que os magistrados provinciais, quando a actio iudicati se processava diante deles, podiam conceder ao autor) se verificava com a ordem do magistrado para que o autor conduzisse o réu, preso, à sua casa, e lá o detivesse, em condição semelhante à de um escravo, para que o réu, com o valor de seu trabalho, pagasse a quantia a que fora condenado (ALVES, 2018, p. 267).
\end{abstract}

Observa-se que, originariamente, as medidas executivas poderiam recair sobre a própria pessoa do executado. Portanto, o que vigorava no direito romano era a responsabilidade pessoal do devedor, pois o devedor respondia pela dívida com seu corpo, seu trabalho, sua liberdade (JARDIM, 2018). Mas com o passar o tempo, a sociedade evoluiu e juntamente com ela o direito de todos os povos passou a ter características de um pensamento mais humanitário ${ }^{3}$ (ALVES, 2018).

\footnotetext{
${ }^{3}$ Quando a humanidade saiu da idade média e entrou moderna, que também fora chamada de iluminismo, o ser humano passou a deixar mais de lado a explicação religiosa sobre tudo que acontecia no mundo começando a usar a racionalidade para explicar os fenômenos que aconteciam em sociedade, e esses acontecimentos tiveram interferência direta no direito que começou a tomar o rumo diferente para chegar até onde se chegou, tendo sido conquistados inúmeros direitos pelos povos suprimidos ao longo da história, até se chegar a idade contemporânea (ALVES, 2018).
}

Acad. Dir. (ISSNe: Em processo de criação) 
Modificaram-se, então, as medidas executivas utilizadas contra o devedor, que passou a responder pela dívida somente com seus bens, seu patrimônio (NEVES, 2017). Consolidou-se, assim, no ordenamento jurídico o que hoje se denomina responsabilidade patrimonial. Na legislação processual civil brasileira, este princípio está firmado no art. 789 do Código de Processo Civil, que estabelece: "O devedor responde com todos os seus bens presentes e futuros para o cumprimento de suas obrigações, salvo as restrições estabelecidas em lei" (BRASIL, 2015).

Para efetivar a responsabilidade patrimonial são utilizadas as medidas executivas, que podem ser de coerção ou de sub-rogação. As medidas coercitivas visam constranger psicologicamente o executado, a fim de que este pratique os atos necessários à realização do crédito exequendo. São exemplos de medidas coercitivas a multa, a prisão civil do devedor de alimentos, o protesto de título executivo ou a anotação do nome do devedor em cadastros de inadimplentes (CÂMARA, 2018).

Já os meios de sub-rogação são aqueles em que a atividade executiva substitui a atuação do executado, pois produz um resultado prático equivalente ao que se teria se o próprio executado tivesse adimplido a prestação. É o que acontece, por exemplo, quando se realiza a penhora de bens do executado para satisfazer o crédito exequendo, ou quando realiza a busca e apreensão de um bem para entregá-lo ao exequente. Tanto os meios ou medidas de coerção quanto os de sub-rogação, compõem as chamadas medidas executivas (CÂMARA, 2018).

Dentro desta sistemática processual, existem dois tipos de medidas que são utilizadas caso o devedor solvente não cumpra com a obrigação a ele imputada, que são chamadas de típicas e atípicas. Em regra, primeiramente devem ser esgotadas todas as possibilidades típicas previstas em lei para que posteriormente seja adotado pelo magistrado técnicas processuais diversas daquelas comuns para tentar efetivar o processo de execução.

\subsubsection{Medidas Executivas Típicas}

A execução por quantia certa tem como finalidade a satisfação do credor a partir de meios legais eficazes visando o patrimônio do devedor.

Medidas executivas típicas são aquelas previstas em lei, pelas quais o juiz tenta, no caso concreto, a satisfação do direito do exequente. São exemplos desses 
meios previstos em lei: penhora, expropriação, busca e apreensão, astreintes, arresto executivo, remoção de pessoas ou coisas, fechamento de estabelecimentos comerciais. Mas convém observar que as medidas típicas compõem um meramente exemplificativo, pois o juiz pode adotar outros meios executivos que não estejam expressamente consagrados em lei (NEVES, 2018).

Tratando-se de execução por quantia certa, a penhora é uma das medidas típicas de execução mais utilizadas, tendo previsão legal no art. 835 , do $\mathrm{CPC}^{4}$, que traz um rol de bens penhoráveis, organizados conforme ordem preferência para realização da penhora (BRASIL, 2015). A penhora é, portanto, a constrição judicial de um bem, visando à garantia da execução. Pode ser conceituada como o ato jurídico processual executivo que fixa a responsabilidade patrimonial do executado sobre um ou mais bens individualizados do seu acervo com vista à satisfação efetiva do direito do credor (GAJARDONI et al, 2018)

A penhora como preconiza o artigo supracitado, tem como prioridade o dinheiro onde está é feita na modalidade online através do sistema BacenJud ${ }^{5}$ que bloqueia valores nas constas do executado para garantir a execução (BRASIL, 2015). Outro sistema bastante utilizado para facilitar a penhora é o Renajud, que pesquisa veículos registrados em nome da parte devedora para que possa ser realizada a penhora e satisfazer o valor devido. E, tem-se ainda o InfoJud que busca informações dos

\footnotetext{
${ }^{4}$ Art. 835. A penhora observará, preferencialmente, a seguinte ordem: I - dinheiro, em espécie ou em depósito ou aplicação em instituição financeira; II - títulos da dívida pública da União, dos Estados e do Distrito Federal com cotação em mercado; III - títulos e valores mobiliários com cotação em mercado; IV - veículos de via terrestre; V - bens imóveis; VI - bens móveis em geral; VII semoventes; VIII - navios e aeronaves; IX - ações e quotas de sociedades simples e empresárias; X - percentual do faturamento de empresa devedora; XI - pedras e metais preciosos; XII - direitos aquisitivos derivados de promessa de compra e venda e de alienação fiduciária em garantia; XIII outros direitos. $\S 1^{\circ}$ É prioritária a penhora em dinheiro, podendo o juiz, nas demais hipóteses, alterar a ordem prevista no caput de acordo com as circunstâncias do caso concreto. $\S 2^{\circ}$ Para fins de substituição da penhora, equiparam-se a dinheiro a fiança bancária e o seguro garantia judicial, desde que em valor não inferior ao do débito constante da inicial, acrescido de trinta por cento. $\S 3^{\circ}$ $\mathrm{Na}$ execução de crédito com garantia real, a penhora recairá sobre a coisa dada em garantia, e, se a coisa pertencer a terceiro garantidor, este também será intimado da penhora.

${ }^{5} \mathrm{O}$ BacenJud é um sistema que interliga a Justiça ao Banco Central e as instituições bancárias, para agilizar a solicitação de informações e o envio de ordens judiciais ao Sistema Financeiro Nacional, via internet. Por meio do BacenJud os juízes, com senha previamente cadastrada, preenchem um formulário na internet solicitando as informações necessárias a determinado processo com o objetivo de penhora on-line ou outros procedimentos judiciais. A partir daí, a ordem judicial é repassada eletronicamente para os bancos, reduzindo o tempo de tramitação do pedido de informação ou bloqueio e, em consequência, dos processos (CONSELHO NACIONAL DE JUSTIÇA, 2020).
} 
executados junto à Receita Federal, consultando as declarações de importo de renda (CONSELHO NACIONAL DE JUSTIÇA, 2020).

Estas medidas citadas são as mais comuns no processo de execução na sua modalidade típica, contudo, nem sempre são exitosas. Neste caso, o credor pode recorrer para as medidas atípicas de execução, que buscam por meio de outras técnicas processuais materializar a decisão judicial, entregando ao credor o que lhe é de direito.

\subsubsection{Medidas Executivas Atípicas}

A partir da análise das medidas executivas típicas, conclui-se que é tarefa impossível para o legislador prever todas as particularidades dos direitos merecedores de tutela executiva e estabelecer meios executivos diferenciados considerando essas particularidades. Diante dessa realidade, a tipicidade dos meios executivos perdeu seu espaço para o princípio da atipicidade (DIDIER JUNIOR et al, 2017)

A atipicidade dos meios executivos foi consagrada Código de Processo Civil de 1973, já revogado, que em seu art. $461, \S 5 .^{\circ 6}$, que possibilitava a utilização de todas as medidas necessárias, no cumprimento de obrigação de fazer ou não fazer, para a efetivação da tutela específica ou a obtenção do resultado prático equivalente. Utilizava, ainda, a expressão "tais como", em nítida demonstração do caráter exemplificativo do rol legal. O artigo supramencionado do, já revogado, CPC/73 legitimava a utilização de meios atípicos para se obter o resultado útil do processo (NEVES, 2017).

Com a entrada em vigor do Código de Processo Civil em 2015, ampliou-se o rol de hipóteses de adoção de medidas atípicas, passando a ter previsão legal no artigo 139, IV, que atribui ao juiz o poder de "determinar todas as medidas indutivas, coercitivas, mandamentais ou sub-rogatórias necessárias para assegurar o

\footnotetext{
${ }^{6}$ Art. 461. Na ação que tenha por objeto o cumprimento de obrigação de fazer ou não fazer, o juiz concederá a tutela específica da obrigação ou, se procedente o pedido, determinará providências que assegurem o resultado prático equivalente ao do adimplemento. [...] § 5 o Para a efetivação da tutela específica ou a obtenção do resultado prático equivalente, poderá o juiz, de ofício ou a requerimento, determinar as medidas necessárias, tais como a imposição de multa por tempo de atraso, busca e apreensão, remoção de pessoas e coisas, desfazimento de obras e impedimento de atividade nociva, se necessário com requisição de força policial (BRASIL, 1973).
} 
cumprimento de ordem judicial, inclusive nas ações que tenham por objeto prestação pecuniária" (BRASIL, 2015).

O dispositivo supracitado permite a aplicação ampla e irrestrita do princípio da atipicidade a qualquer espécie de execução, independentemente da natureza da obrigação. Inclusive com relação a possibilidade de estabelecer astreintes nas execuções de obrigação de pagar quantia certa. São exemplos de medidas atípicas: suspensão do direito do devedor de conduzir veículo automotor, inclusive com a apreensão física da $\mathrm{CNH}$; vedação de contratação de novos funcionários por empresa devedora de verbas salariais; proibição de empréstimo de devedor que não paga débito relativo a financiamento bancário (NEVES, 2018).

Pode-se conceituar a atipicidade das medidas atípicas com sendo um mecanismo conferido ao juiz para forçar o devedor a cumprir a obrigação a ele imposta. Neste norte, a base legal que confere ao juiz o poder discricionário de adotar medidas executivas adversas para satisfazer a tutela jurisdicional do interessado, esta consagrada no artigo 139, IV do CPC, que diz:

Art. 139. O juiz dirigirá o processo conforme as disposições deste Código, incumbindo-lhe:

$[\ldots]$

IV - determinar todas as medidas indutivas, coercitivas, mandamentais ou sub-rogatórias necessárias para assegurar o cumprimento de ordem judicial, inclusive nas ações que tenham por objeto prestação pecuniária (BRASIL, 2015);

Seguindo este raciocínio, deve-se, de início, compreender literalmente o que o art. 139, IV, possibilita ao juiz na fase executiva, e para tanto, Cássio Scarpinella Bueno conceitua a definição do que é o artigo 139, IV, como uma regra de flexibilização das técnicas executivas que consolida o poder-dever geral executivo do juiz. Nas palavras do autor:

[...] regra que convida à reflexão sobre o CPC de 2015 ter passado a admitir, de maneira expressa, verdadeira regra de flexibilização das técnicas executivas, permitindo ao magistrado, consoante as peculiariedades de cada caso concreto, modificar o modelo preestabelecido pelo código, determinando a adoção, sempre de forma fundamentada, dos mecanismos que mostrem mais adequados para a satisfação do direito, levando em conta as peculiariedades do caso concreto. Um verdadeiro dever-poder geral executivo, portanto. Aceita esta proposta, que, em última análise, propõe a adoção de um modelo atípico de atos executivos, ao lado da tipificação feita pelos arts. 513 a 538, que disciplinam o cumprimento de sentença, e ao longo 
de todo o livro II da parte especial, voltado ao processo de execução, será correto ao magistrado flexibilizar as regras previstas naqueles dispositivos codificados consoante se verifiquem insuficientes para a efetivação da tutela jurisdicional (BUENO, 2015, p. 165).

Portanto com a elucidação doutrinária, fica cristalino a definição de que o art. 139, IV representa um poder discricionário que o magistrado tem de aplicar meios atípicos de natureza indutiva, coercitiva, mandamental ou sub-rogatória com intuito de proporcionar uma maior efetividade no processo de execução sempre analisando as singularidades de cada caso concreto.

É importante destacar que no processo de execução existem duas formas executivas, a execução direta e a execução indireta. A execução direta ou por subrogação ocorre quando se retira o bem do executado e é entregue ao exequente, substituindo a vontade do devedor pela vontade do direito, gerando a satisfação da obrigação devida. Já a execução indireta pode ser patrimonial ou pessoal, onde está incide diretamente na pessoa do executado, onde prejudique sua condição dentro do processo coagindo o devedor a cumprir a obrigação, tendo como técnicas executivas a imposição de multa e a prisão civil, no caso de não pagamento de pensão alimentícia (DIDIER JR.; BRAGA; CUNHA, 2017). As medidas executivas atípicas atuam na esfera de execução indireta, pois buscam a coerção do devedor ao cumprimento da obrigação.

Essa ampliação nos poderes do juiz representou uma grande evolução legislativa no âmbito do processo civil brasileiro e será analisada a seguir.

\section{APLICABILIDADE PRÁTICA DAS MEDIDAS EXECUTIVAS ATÍPICAS CONFORME ARTIGO 139, IV, DO CPC/15}

A palavra atipicidade no mundo do direito significa dizer que tal conduta ou ato praticado não tem previsão legal expressamente prevista no ordenamento jurídico. Nos dizeres de Luís Roberto Barroso (1993, p. 79), "a efetividade significa, a realização do Direito, o desempenho concreto de sua função social". Com isso significa dizer que os meios atípicos, por mais que sejam subsidiários das medidas típicas, representam a possibilidade da aproximação do cumprimento da obrigação de acordo com a realidade social apresentada em cada caso concreto. 
O princípio da atipicidade, como já mencionado, está previsto no artigo 139, IV, do $\mathrm{CPC} / 15$ e se refere à faculdade que o juiz tem para adotar meios não previstos em lei para dar mais efetividade ao processo de execução. No que concerne a natureza jurídica destes meios atípicos, o próprio artigo 139, VI deixa claro que a natureza indutiva, coercitiva, sub-rogatória, mandamental possuem as mesmas finalidades (BRASIL, 2015).

Portanto, constata-se que a natureza jurídica dos meios atípicos de execução que estão presentes de um modo intrínseco, está diretamente ligado a possibilidade de flexibilização da norma jurídica positivada, não se limitando apenas as vias ordinárias, e isso faz com que seja possível atingir a sua essência, ou seja, sua finalidade principal com a maior efetividade possível (RODRIGUES,2015).

\subsection{APLICABILIDADE PRÁTICA DO ARTIGO 139, IV, DO CPC/15}

Como já se sabe, o artigo 139, IV, do CPC, dá poderes discricionários ao juiz para que o mesmo se utilize de medidas atípicas, indutivas, coercitivas, sub-rogatórias e mandamentais, para satisfazer o direito do jurisdicionado caso os meios tipicamente previstos não surtirem efeitos.

As medidas atípicas estão sendo cada vez mais usadas dentro do direito devido a vários fatores, e um deles é a ocultação de bens e valores por parte do executado. Várias são as medidas atípicas já adotadas pelos magistrados no processo civil brasileiro com base no art. 139, IV, como por exemplo a apreensão da $\mathrm{CNH}$, do passaporte, o bloqueio de cartão de crédito, dentre outras técnicas executivas usadas pelos magistrados. Acerca do tema, o professor Daniel Amorim Assumpção Neves, ensina que:

Em outras palavras, a adoção de medidas atípicas, em especial de natureza coercitiva, previstas no art. 139, IV, do Novo CPC, deve ser dirigida ao devedor que não paga porque não quer e não para aquele que não paga porque não pode. Várias são as medidas atípicas já adotadas pelos magistrados no processo civil brasileiro com base no art. 139, IV, como por exemplo a apreensão da $\mathrm{CNH}$, do passaporte, o bloqueio de cartão de crédito, dentre outras técnicas executivas usadas pelos magistrados (NEVES, 2017, p. 123). 
Ainda nesse prisma, cita-se a decisão do Egrégio Tribunal de Justiça de Minas Gerais que demonstra a utilização de medidas não previstas na lei:

EMENTA: AGRAVO DE INSTRUMENTO - CUMPRIMENTO DE SENTENÇA - APREENSÃO DE PASSAPORTE E SUSPENSÃO DE CARTEIRA NACIONAL DE HABILITAÇÃO (CNH) - EFETIVIDADE DA EXECUÇÃO MEDIDAS DESARRAZOÁVEIS E DESPROPORCIONAIS-CASO CONCRETO. 1. Nos termos do inciso IV, do art. 139, do CPC, é permitido ao magistrado determinar quaisquer medidas necessárias para assegurar 0 cumprimento da ordem judicial, inclusive nas ações que tem por objeto apenas a prestação pecuniária. 2. A utilização de medidas coercitivas indiretas apenas é cabível se representar efetividade à execução e desde que observado o princípio da razoabilidade, ponderando-se os direitos envolvidos (MINAS GERAIS,2020).

Como visto acima, a apreensão da carteira nacional de habilitação (CNH) é uma das hipóteses de medidas adotas pelo magistrado com fulcro no inciso IV, do Artigo 139 do CPC na tentativa de fazer com que a execução se torne mais exitosa. Convém observar, ainda, a decisão abaixo, proferida na $5^{\text {a }}$ Vara Cível da Comarca de Presidente Prudente/SP, em que o magistrado autorizou a apreensão da $\mathrm{CNH}$ de um ex-jogador de futebol, sob o fundamento de que não há violação de nenhuma necessidade substancial do indivíduo, pois este não se utiliza da habilitação para exercer atividade profissional, tampouco pode fazer com que ele seja impedido de ir e vir de outro modo. Somente se utiliza estes aparatos coercitivos para tentar fazer com que a execução logre êxito, tendo em vista que nestes casos o devedor possui condições de arcar com a quantia devida, porém não o faz:

\begin{abstract}
Vistos. O exequente formulou pedido para aplicação de medidas atípicas ao executado como a retenção da $\mathrm{CNH}$. O pedido para retenção da $\mathrm{CNH}$, como aplicação de medida atípica, dotada de caráter coercitivo ao pagamento da dívida, não implica em violação ao direito de ir e vir $A$ jurisprudência do Superior Tribunal de Justiça já se posicionou neste sentido. Com efeito, o executado não se utiliza da $\mathrm{CNH}$ para exercício de sua profissão, ou seja, não é motorista profissional, e a retenção de sua $\mathrm{CNH}$ não viola o direito de ir e vir do cidadão, pois que o DETRAN já tem utilizado amplamente a suspensão e até a cassação da $\mathrm{CNH}$ como medida administrativa aplicada a motoristas infratores. O executado poderá se locomover a qualquer momento e para qualquer lugar usando meios de transporte disponíveis e desde que não o faça como condutor do veiculo. Assim, acolho o pedido do exequente para determinar que se oficie à CIRETRAN/DETRAN local para adotar as medidas necessárias à retenção da $\mathrm{CNH}$ do executado. Intime-se. Presidente Prudente, 19 de junho de 2020 (PRESIDENTE PRUDENTE, 2020).
\end{abstract}


É notório que as técnicas coercitivas atípicas que trazem consigo o inciso IV do artigo 139 do CPC, servem para dar ao processo de execução a devida efetividade sem que o executado seja desprovido de seus direitos e garantias fundamentais.

Por outro lado, destaca-se que não é em todas as situações que o Magistrado deve valer-se de medidas coercitivas atípicas, além de primeiramente comprovar a ineficácia das vias ordinárias. Na decisão abaixo citada, nota-se que o Tribunal de Justiça Catarinense já entendeu de modo contrário com relação à adoção de técnicas executivas atípicas:

AGRAVO DE INSTRUMENTO. CUMPRIMENTO DE SENTENÇA. DECISÃO DE INDEFERIMENTO DO PEDIDO DE SUSPENSÃO DE CARTEIRA NACIONAL DE HABILITAÇÃO (CNH) E APREENSÃO DE PASSAPORTE DA PARTE EXECUTADA. INSURGÊNCIA DA EXEQUENTE. PLEITO DE UTILIZAÇÃO DOS MEIOS COERCITIVOS DISPOSTOS NO ART. 139, IV, DO CPC/2015, ANTE O ESGOTAMENTO DE TENTATIVAS DE RECUPERAÇÃO DE CRÉDITO CABÍVEIS. IMPOSSIBILIDADE. MEDIDA DESPROPORCIONAL QUE POSSUI EFETIVIDADE INCERTA E FERE DIREITO DE IR E VIR À LUZ DO ART. 5०, XV, DA CF/88. DECISÃO MANTIDA. PRECEDENTES DO STJ E DESTA CORTE. RECURSO CONHECIDO E DESPROVIDO (SANTA CATARINA, 2020).

Visto isso, percebe-se que nem sempre se aplica estas medidas adversas durante a execução ou cumprimento de sentença, eis que sempre é feita uma análise de antemão pelo Magistrado para verificar se é cabível e adequada a adoção de tais medidas para efetivar o direito do executado sem ferir direitos e garantias fundamentais do executado.

\subsection{COLISÃO DE DIREITOS FUNDAMENTAIS}

A colisão de princípios dentro do ordenamento jurídico brasileiro é o choque entre duas fontes do direito, de modo que caberá aos estudiosos da ciência do direito fazer uso dos princípios da proporcionalidade e razoabilidade para que um deles seja ponderado em favor de um bem jurídico com maior relevância (FARIAS, 2000).

Na sequência deve-se entender o que são e quais são os direitos fundamentais. Podemos conceituar os direitos fundamentais, na visão de José Afonso da Silva (2005, p.178) como aqueles "direitos atinentes a situações jurídicas sem as quais a pessoa humana não se realiza, não convive e, às vezes, nem mesmo sobrevive". $O$ 

CPC

rol de direitos fundamentais está previsto na Constituição Federal de 1988, mais precisamente no caput do art. $5^{\circ}$ da $\mathrm{CF} / 88$, que diz: "Todos são iguais perante a lei, sem distinção de qualquer natureza, garantindo-se aos brasileiros e aos estrangeiros residentes no País a inviolabilidade do direito à vida, à liberdade, à igualdade, à segurança e à propriedade, nos termos seguintes" (BRASIL,1988).

Tamanha é a importância deste artigo que na atual Constituição Brasileira este dispositivo tem "status" de cláusula pétrea, ou seja, não poderá ser alterado, salvo para dar mais amplitude aos direitos fundamentais tutelados por este artigo (SIMÕES NETO, 2006).

Este choque entre duas fontes do direito também ocorre no processo de execução quando se trata de meios atípicos de execução, pois, o juiz tem poder discricionário de adotar medidas coercitivas distintas das já previstas para que possa satisfazer o direito do interessado. Estas medidas vão desde apreensão do passaporte até o bloqueio de cartão de crédito do executado, onde é ai que ocorre a colisão de certos princípios, como por exemplo, o princípio da satisfação da tutela jurisdicional se choca com o princípio da liberdade juntamente com o direito de ir e vir do executado (FARIAS, 2000).

Neste sentido, para elucidar o entendimento sobre o tema abordado, o Superior Tribunal de Justiça em seu posicionamento sobre do art. 139, IV, diz que:

\begin{abstract}
A adoção de medidas de incursão na esfera de direitos do executado, notadamente direitos fundamentais, carecerá de legitimidade e configurar-seá coação reprovável, sempre que vazia de respaldo constitucional ou previsão legal e à medida em que não se justificar em defesa de outro direito fundamental. A liberdade de locomoção é a primeira de todas as liberdades, sendo condição de quase todas as demais. Consiste em poder o indivíduo deslocar-se de um lugar para outro, ou permanecer cá ou lá, segundo Ihe convenha ou bem the pareça, compreendendo todas as possíveis manifestações da liberdade de ir e vir. Revela-se ilegal e arbitrária a medida coercitiva de suspensão do passaporte proferida no bojo de execução por título extrajudicial (duplicata de prestação de serviço), por restringir direito fundamental de ir e vir de forma desproporcional e não razoável. Não tendo sido demonstrado o esgotamento dos meios tradicionais de satisfação, a medida não se comprova necessária (BRASIL, 2018a).
\end{abstract}

O STJ, portanto, considerou a liberdade de locomoção do executado como essencial, a primeira de todas as liberdades, afastando a possibilidade de restrição à essa liberdade sem o esgotamento dos meios tradicionais de satisfação do crédito, por considerá-la desproporcional e não razoável. Portanto, constata-se que sempre 
que houver dois princípios constitucionais juridicamente tutelados em colisão, devese observar conforme o caso, o que será considerado de maior relevância jurídica para o direito em cada caso.

No mesmo sentido, Fernanda Tartuce, faz ressalvas ao uso desse instituto que sob sua ótica nada mais é do que um amplo poder discricionário do juiz sem balizas específicas que podem acabar se tornando inapropriadas, afirmando o autor que "nessa linha, suspender o direito de dirigir e restringir o uso de passaporte são iniciativas problemáticas, por atingirem a pessoa do devedor, enquanto a penhora da restituição de Imposto de Renda soa viável por afetar seu patrimônio" (TARTUCE, 2016, n.p.).

Ainda acerca da aplicabilidade do art. 139, IV, Guilherme Pupe da Nóbrega (2016) vai além e afirma que estes meios executivos possuem limitação nos direitos fundamentais, sendo assim, padecendo de inconstitucionalidade as medidas que suspendem a Carteira Nacional de Habilitação ( $\mathrm{CNH})$, e a apreensão do passaporte, pois ofendem a dignidade da pessoa humana e ferem o direito de ir e vir do executado.

Neste norte, cabe ainda ressaltar de que apesar de o Código de Processo Civil de 2015, incluir o inciso IV, do 139, como uma ferramenta para proporcionar uma maior efetividade no cumprimento das decisões judicias, há ressalvas no próprio CPC, que asseguram um processo mais justo em todas as suas fases, e é claro, principalmente na fase da execução. Para tanto, o artigo $8^{\circ}$ do CPC elucida que: "Ao aplicar o ordenamento jurídico, o juiz atenderá aos fins sociais e às exigências do bem comum, resguardando e promovendo a dignidade da pessoa humana e observando a proporcionalidade, a razoabilidade, a legalidade, a publicidade e a eficiência" (BRASIL, 2015).

Dito isso, verifica-se que o processo civil observará todos os requisitos previstos acima, para assim ser considerado além de um processo mais adequado e assim fazendo justiça entre as partes, evitando-se excessos.

\section{PARÂMETRO PARA A APLICAÇÃO E EFETIVIDADE DAS MEDIDAS COERCITIVAS ATÍPICAS}

Como se sabe, para a aplicação de toda e qualquer lei devem ser observados seus critérios para que esta norma se encaixe perfeitamente ao caso concreto. Isso 

CPC

porque o legislador não tem o poder de fazer o que bem entender, a hora que quiser com a legislação posta no sistema jurídico brasileiro, evitando que os indivíduos possam ser vítimas de normas jurídicas arbitrarias, que não condizem com a realidade social do povo brasileiro. Por isso há de se enaltecer que os meios coercitivos atípicos não são conferidos a juiz como se fosse um poder ilimitado, tendo o magistrado sempre quando for proferir uma sentença, deverá dar a ela a devida fundamentação (WAMBIER et al,2015).

Este princípio está consagrado na Constituição Federal de 1988, em seu artigo 93, inciso $I X^{7}$, seguindo neste prisma a clássica doutrina processual civil também enaltece essa necessidade, onde

Dado relevante é a atribuição de dignidade constitucional, em mais de um país, ao dever, imposto aos juízes, de motivar as decisões. O fenômeno não esgota suas ignificação no acréscimo de estabilidade que assim se imprime à norma, colocada ao abrigo das vicissitudes legislativas em nível ordinário; sugere, a de mais, visualização diversa da matéria, pela adequada valoração de seu enquadramento num sistema articulado. De garantias fundamentais. (BARBOSA MOREIRA, 1988, p. 282)

Com isso, fica cristalino o dever de o juiz fundamentar suas decisões, ainda mais quando se trata de um poder discricionário que a lei lhe confere.

Além da devida fundamentação, outro parâmetro muito importante que o Magistrado deve levar em consideração é primeiramente esgotar todas as vias ordinárias de execução, para que depois, se necessário, adote medidas atípicas para tentar cumprir a obrigação, conforme orienta o Enunciado $n^{\circ} 12$ do Fórum Permanente De Processualistas Civis, que diz:

\begin{abstract}
A aplicação das medidas atípicas sub-rogatórias e coercitivas é cabível em qualquer obrigação no cumprimento de sentença ou execução de título executivo extrajudicial. Essas medidas, contudo, serão aplicadas de forma subsidiária às medidas tipificadas, com observação do contraditório, ainda que diferido, e por meio de decisão à luz do art. 489, $\S 1^{\circ}$, I e II. (Grupo: Execução) (ENUNCIADOS, 2019, p. 13).
\end{abstract}

\footnotetext{
${ }^{7}$ Art. 93. Lei complementar, de iniciativa do Supremo Tribunal Federal, disporá sobre o Estatuto da Magistratura, observados os seguintes princípios: [...] IX todos os julgamentos dos órgãos do Poder Judiciário serão públicos, e fundamentadas todas as decisões, sob pena de nulidade, podendo a lei limitar a presença, em determinados atos, às próprias partes e a seus advogados, ou somente a estes, em casos nos quais a preservação do direito à intimidade do interessado no sigilo não prejudique o interesse público à informação. (BRASIL, 1988)
} 
Posto isto, há de se enaltecer que, por mais que o juiz adote o uso destas medidas, deverá sempre ser oportunizado o contraditório, como menciona o enunciado acima citado.

Como já mencionado anteriormente, a devida fundamentação como sendo um dos parâmetros mais importantes para adotar estes meios coercitivos, também se faz necessário que o juiz demonstre que estas medidas não se mostram adequadas a determinado caso em particular, como se vê na decisão abaixo, proferida pelo Superior Tribunal de Justiça no Recurso Especial n 1.782.418:

RECURSO ESPECIAL. AÇÃO DE COMPENSAÇÃO POR DANO MORAL E REPARAÇÃO POR DANO MATERIAL. CUMPRIMENTO DE SENTENÇA. QUANTIA CERTA. MEDIDAS EXECUTIVAS ATÍPICAS. ART. 139, IV, DO $\mathrm{CPC} / 15$

CABIMENTO. DELINEAMENTO DE DIRETRIZES A SEREM OBSERVADAS PARA SUA APLICAÇÃO.

1. Ação distribuída em 10/6/2011. Recurso especial interposto em 25/5/2018. Autos conclusos à Relatora em 3/12/2018. 2. O propósito recursal é definir se, na fase de cumprimento de sentença, a suspensão da carteira nacional de habilitação e a retenção do passaporte do devedor de obrigação de pagar quantia são medidas viáveis de serem adotadas pelo juiz condutor do processo. 3. O Código de Processo Civil de 2015, a fim de garantir maior celeridade e efetividade ao processo, positivou regra segundo a qual incumbe ao juiz determinar todas as medidas indutivas, coercitivas, mandamentais ou sub-rogatórias necessárias para assegurar o cumprimento de ordem judicial, inclusive nas ações que tenham por objeto prestação pecuniária (art. 139,IV). 4. A interpretação sistemática do ordenamento jurídico revela, todavia, que tal previsão legal não autoriza a adoção indiscriminada de qualquer medida executiva, independentemente de balizas ou meios de controle efetivos.5. De acordo com o entendimento do STJ, as modernas regras de processo, ainda respaldadas pela busca da efetividade jurisdicional, em nenhuma circunstância poderão se distanciar dos ditames constitucionais, apenas sendo possível a implementação de comandos não discricionários ou que restrinjam direitos individuais de forma razoável. Precedente específico.6. A adoção de meios executivos atípicos é cabível desde que, verificando-se a existência de indícios de que o devedor possua patrimônio expropriável, tais medidas sejam adotadas de modo subsidiário, por meio de decisão que contenha fundamentação adequada às especificidades da hipótese concreta, com observância do contraditório substancial e do postulado da proporcionalidade.7. Situação concreta em que o Tribunal a quo indeferiu o pedido do exequente de adoção de medidas executivas atípicas sob o singelo fundamento de que a responsabilidade do devedor por suas dívidas diz respeito apenas ao aspecto patrimonial, e não pessoal. 8. Como essa circunstância não se coaduna com o entendimento propugnado neste julgamento, é de rigor - à vista da impossibilidade de esta Corte revolver o conteúdo fático-probatório dos autos - o retorno dos autos para que se proceda a novo exame da questão.9. De se consignar, por derradeiro, que o STJ tem reconhecido que tanto a medida de suspensão da Carteira Nacional de Habilitação quanto a de apreensão do passaporte do devedor recalcitrante não estão, em abstrato e de modo geral, obstadas de serem adotadas pelo juiz condutor do processo executivo, devendo, contudo, observar-se o 
preenchimento dos pressupostos ora assentados. Precedentes. RECURSO ESPECIAL PROVIDO (BRASIL, 2018b).

Ainda neste sentido, destaca-se decisão semelhante proferida no Recurso Especial $n^{0} 1.788 .950^{8}$, em que não fora acolhido o pedido de aplicação de medidas atípicas pois não há sinais de que o devedor esteja ocultando patrimônio, e sim de que não possui, de fato, bens aptos a serem expropriados (BRASIL, 2019)

Nestes dois exemplos, ambos de relatoria da Ministra Nancy Andrighi, percebese que este dispositivo de lei não será aplicado em todos os casos como se fosse uma regra geral, pois há de se verificar as peculiaridades de cada caso concreto para ter certeza de que a adoção de medidas coercitivas se mostrará útil para lograr êxito, entregando ao exequente o que de direito the cabe sem que o executado sofra nenhum excesso.

\subsection{EFETIVIDADE DO PROCESSO DE EXECUÇÃO A LUZ DO ARTIGO 139, IV DO CPC}

Todos os estudos acerca desde novo dispositivo de lei, evidenciam a importância que têm que as medidas previstas no artigo 139, IV, dentro do processo civil. Contudo, conforme a lição de Alexandre Freitas Câmara (2018), a adoção deste dispositivo somente se dará após serem esgotados todas as medidas ordinárias executivas, como BacenJud, Renajud, Infojud, dentre outras previstas em lei.

Sabe-se que o simples reconhecimento de um direito a uma pessoa a depender do tipo da ação nem sempre é o suficiente, deve-se satisfazer a tutela jurisdicional do interessado através da materialização do direito, entregando ao 8 RECURSO ESPECIAL. EXECUÇÃO DE TÍTULO EXTRAJUDICIAL. CHEQUES. VIOLAÇÃO DE
DISPOSITIVO CONSTITUCIONAL. DESCABIMENTO. MEDIDAS EXECUTIVAS ATÍPICAS. ART.
139, IV, DO CPC/15. CABIMENTO. DELINEAMENTO DE DIRETRIZES A SEREM OBSERVADAS
PARA SUA APLICAÇÃO. [...] 7. A adoção de meios executivos atípicos é cabível desde que,
verificando-se a existência de indícios de que o devedor possua patrimônio expropriável, tais medidas
sejam adotadas de modo subsidiário, por meio de decisão que contenha fundamentação adequada
às especificidades da hipótese concreta, com observância do contraditório substancial e do postulado
da proporcionalidade. 8. Situação concreta em que o Tribunal a quo indeferiu o pedido do recorrente
de adoção de medidas executivas atípicas sob o fundamento de que não há sinais de que o devedor
esteja ocultando patrimônio, mas sim de que não possui, de fato, bens aptos a serem expropriados.
9. Como essa circunstância se coaduna com o entendimento propugnado neste julgamento, é de rigor
- à vista da impossibilidade de esta Corte revolver o conteúdo fático-probatório dos autos - a
manutenção do aresto combatido. RECURSO ESPECIAL PARCIALMENTE CONHECIDO E NÃO
PROVIDO.

Acad. Dir. (ISSNe: Em processo de criação) 
jurisdicionado o que lhe é devido, e, é justamente para isso que serve o processo de execução, para dar efetividade a todo processo civil (BOECKEL,2005).

Nas palavras de Gonçalves (2019, p. 6), esta é "a importância extraordinária da execução. Sem ela, o titular de um direito estaria privado da possibilidade de satisfazer-se sem a colaboração do devedor". Portanto fica transparente que o processo de execução é uma das fases mais importantes de toda a sistemática processual, devendo ser usado todas as técnicas e ferramentas, dispostas em lei, ou sob o poder discricionário do juiz (que é o caso do artigo 139, IV), para se obter o cumprimento da obrigação contida no título executivo, entregando ao indivíduo o que de direto lhe é devido.

No que tange a efetividade deste dispositivo legal, este assunto ainda é alvo de muita polêmica no Brasil, pois, como já fora abordado, envolve direitos e garantias fundamentais previstos na Constituição Federal. O artigo 139, IV do CPC, como já visto anteriormente, é o dispositivo de lei onde as medidas adversas das ordinárias estão positivadas, já foi objeto de uma Ação Direta de Inconstitucionalidade (ADI $\mathrm{n}^{\circ}$ 5941DF) ingressada pelo Partido dos Trabalhadores no STF, havendo um pedido de medida cautelar, entretanto a matéria ainda não foi analisada, sendo encaminhada ao Tribunal Pleno para julgamento definitivo, conforme decisão do relator Ministro Luiz Fux ${ }^{9}$ :

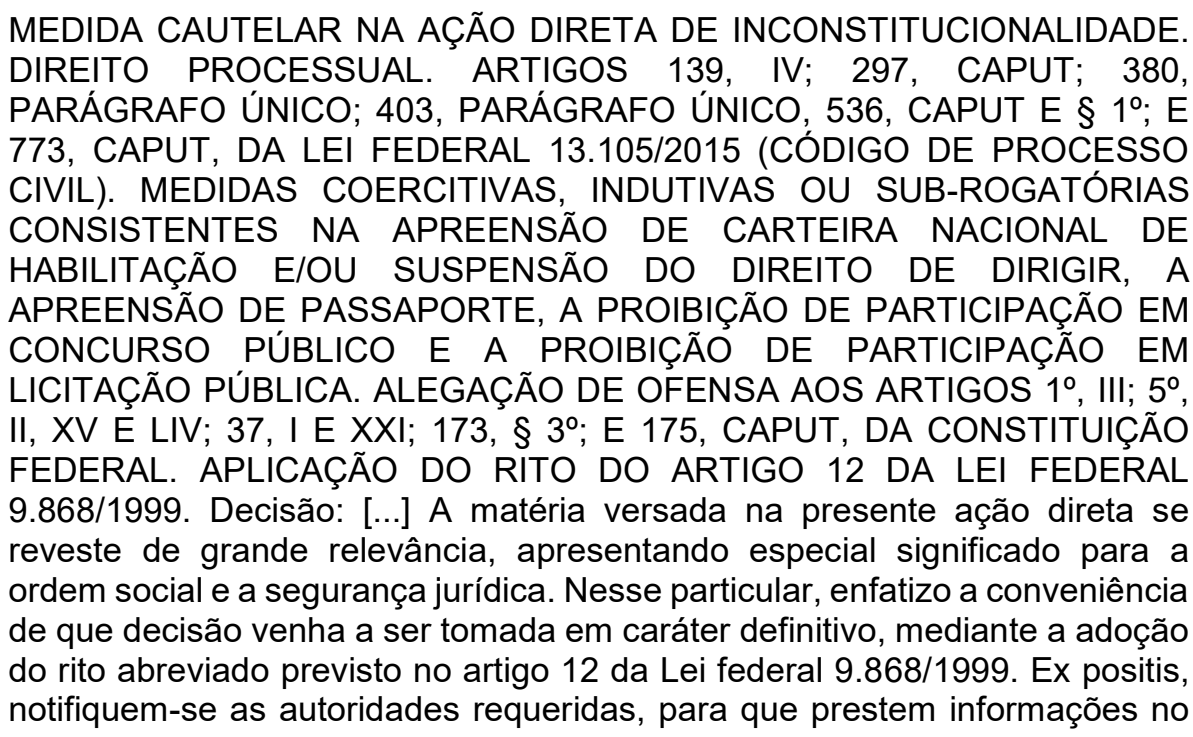

${ }^{9}$ A decisão fora embasada no artigo 12, da Lei 9.868/99 (Lei da Ação Direta de Inconstitucionalidade), que submeter o processo diretamente ao Tribunal, que terá a faculdade de julgar definitivamente a ação (BRASIL, 1999). 
prazo de 10 (dez) dias. [...] (STF - MC ADI: 5941 DF - DISTRITO FEDERAL 0070735-42.2018.1.00.0000, Relator: Min. LUIZ FUX, Data de Julgamento: 17/05/2018, Data de Publicação: DJe-098 21/05/2018) (BRASIL, 2018c)

Neste prisma, verifica-se que estas medidas vêm sendo utilizadas com habitualidade dentro do processo civil brasileiro, como se extrai da decisão do Superior Tribunal de Justiça, proferida no Habeas Corpus nº 558.313:

'HABEAS CORPUS'. PROCESSUAL CIVIL. CPC/15. CUMPRIMENTO DE SENTENÇA. MEDIDAS EXECUTIVAS ATÍPICAS. ART. 139, IV, DO CPC. RESTRIÇÃO DE SAÍDA DO PAÍS SEM PRÉVIA GARANTIA DA EXECUÇÃO. INEXISTÊNCIA DE ILEGALIDADE MANIFESTA. ATENDIMENTO ÀS DIRETRIZES FIXADAS PELAS TURMAS DE DIREITO PRIVADO DO STJ. [...] 3. A adoção desta medida coercitiva atípica, no âmbito do processo de execução, não configura, em si, ofensa direta ao direito de ir e vir do indivíduo, razão pela qual a eventual abusividade ou ilegitimidade da ordem deve ser examinada no caso concreto. 4. Segundo as diretrizes fixadas pela Terceira Turma desta Corte, diante da existência de indícios de que o devedor possui patrimônio expropriável, ou que vem adotando subterfúgios para não quitar a dívida, ao magistrado é autorizada a adoção subsidiária de medidas executivas atípicas, tal como a apreensão de passaporte, desde que justifique, fundamentadamente, a sua adequação para a satisfação do direito do credor, considerando os princípios da proporcionalidade e razoabilidade e observado o contraditório prévio (REsp 1.782.418/RJ e REsp 1788950/MT, Rel. Ministra NANCY ANDRIGHI, TERCEIRA TURMA, julgados em 23/4/2019, DJe 26/4/2019). 5. In casu, a Corte estadual analisou a questão nos moldes estatuídos pelo STJ, não se denotando arbitrariedade na medida coercitiva adotada com fundamento no art. 139, IV, do CPC, pois evidenciada a inefetividade das medidas típicas adotadas, bem como desconsiderada a personalidade jurídica da empresa devedora, uma vez constatada a sua utilização como escudo para frustrar a satisfação do crédito exequendo. 6 . Ausência, ademais, de indicação de meio executivo alternativo menos gravoso e mais eficaz pelos executados, conforme lhes incumbia, nos termos do parágrafo único do art. 805 do CPC/2015. 7. HABEAS CORPUS NÃO CONHECIDO, INEXISTINDO SUBSTRATO PARA O DEFERIMENTO DA ORDEM DE OFÍCIO (BRASIL, 2020).

Portanto, denota-se a importância que possui o inciso IV, do Artigo 139, do CPC, através das medidas serem adotadas para dar mais efetividade na aplicação da legislação brasileira fazendo com que isso garanta a ordem social e a segurança jurídica.

Tamanho significado possui este dispositivo legal que, se caso não houvesse a previsão do inciso, haveria um colapso dentro do ordenamento jurídico brasileiro, como afirma Guilherme Rizzo Amaral (2008, p. 233), "é o engessamento das técnicas de tutela que contribui para a injustiça e a debilidade do processo, seja para o autor, seja para o réu", pois predefinir todas as etapas de um "programa processual" como 
único meio de realizar o direito material "significa algemar o juiz e torná-lo mero espectador ou fiscalizador do funcionamento débil do aparato processual".

Com base nisso é que se pode chegar ao ponto principal desta questão, em que o juiz, a partir do momento em que as partes provocarem o Poder Judiciário, deve conduzir o processo para que este se torne mais célere, justo e efetivo. Com a participação do Magistrado adotando todas as medidas cabíveis necessárias para que ao final do processo seja satisfeito o direito do jurisdicionado.

A partir disso, pode se constatar que, a adoção de técnicas processuais, como as previstas do inciso IV, do 139 , colaboram para que o processo de execução se torne mais justo, célere e efetivo.

\section{CONSIDERAÇÕES FINAIS}

A partir desta pesquisa, constatou-se a importância do processo de execução, pois serve para efetivar os títulos executivos judiciais ou extrajudiciais, entregando ao indivíduo o que lhe é devido por direito. Na sequência, com relação ao inciso IV, do artigo 139 do CPC de 2015, verificou-se que este diploma legal trouxe consigo ferramentas processuais subsidiárias das vias ordinárias de execução que fizeram com que o processo de execução cível se tornasse mais efetivo, célere e justo.

Verificou-se ainda que, apesar das discussões acerca da colisão de direitos fundamentais, as medidas extraordinárias de execução sempre serão aplicadas pelos Magistrados sempre realizando um estudo de cada caso concreto com vistas ao princípio da razoabilidade para aplicação destas medidas. Cabe ressaltar ainda que, nenhum direito na nossa constituição é absoluto, podendo o indivíduo, a depender do caso, ser obrigado a abrir mão deste direito em detrimento da vontade do Estado por um bem jurídico de maior relevância.

Frise-se que, o processo civil vem constantemente se atualizando e caminha a passos largos para uma sistemática processual que visa buscar cada vez mais efetivar o direito, entregando ao indivíduo o que de direito lhe foi assegurado. E, justamente para isso que servem as medidas atípicas de execução previstas no inciso, IV do artigo 139, quando fora esgotado todas as vias ordinárias de execução, o juiz adotará técnicas processuais adversas destas na tentativa de dar ao exequente o que lhe foi prometido em uma sentença ou descrito em algum título executivo extrajudicial. 
Em contrapartida, verificou-se que não é em todos os casos que devem ser aplicadas as medidas previstas no inciso IV, do 139. Os juízes e tribunais ao fazer a análise do caso concreto muitas vezes deixam de aplicar as medidas adversas por não se mostrarem adequadas, isso porque o executado possui direitos os quais devem ser respeitados sob pena de infringir algum direito fundamental, configurando excesso de execução.

Ao final se pode constatar que este estudo realizado na academia, fortalece a importância destes dispositivos de lei, bem como apresenta este tema para outras pessoas que possuem relação com o Direito e também serve para que as pessoas da comunidade que tiverem interesse em conhecer mais sobre a ciência do Direito.

Por fim, conclui-se que adoção das medidas executivas atípicas como ferramenta processual está contribuindo para a construção de um Direito mais justo, efetivo e igualitário a todos, fazendo com que o Direito cumpra com sua função, que nada mais é do que manter a coesão social entre os indivíduos, e, com isso, alcançar um "status" de harmonia jurídica e paz social dentro do Estado Democrático de Direito em que se vive.

\section{REFERÊNCIAS}

ALVES, José Carlos Moreira. Direito romano. 18. ed. rev. Rio de Janeiro: Forense, 2018.

AMARAL, Guilherme Rizzo. Cumprimento e execução da sentença: sob a ótica do formalismo valorativo. Porto Alegre: Livraria do Advogado, 2008.

BARBOSA MOREIRA, José Carlos. A motivação das decisões judiciais como garantia inerente ao Estado de Direito. Temas de direito processual. 2. ed. São Paulo: Saraiva, 1988.

BARROSO, Luís Roberto. O direito constitucional e a efetividade de suas normas: limites e possibilidades da constituição brasileira. 2. ed. Rio de Janeiro: Renovar, 1993.

BOECKEL, Fabrício Dani de. Espécies de tutela jurisdicional. Gênesis Revista de Direito Processual Civil. Curitiba: a. 10, n. 37 p. 432-469, set. 2005.

BUENO, Cassio Scarpinella. Manual de direito processual civil. São Paulo: Saraiva, 2016. 
BRASIL. Constituição Federal da República Federativa do Brasil de 1988. Disponível em: http://www.planalto.gov.br/ccivil_03/constituicao/constituicao.htm. Acesso em: 13 julho 2020.

BRASIL. Lei $n^{\circ}$ 5869, de 11 de janeiro de 1973. Institui o Código de Processo Civil. Disponível em: <http://www.planalto.gov.br/ccivil_03/LEIS/L5869impressao.htm>. Acesso em: 25 fev. 2020.

BRASIL. Lei no 13.105 de 16 de Março de 2015. Código de Processo Civil. Disponível em: http://www.planalto.gov.br/ccivil_03/_ato20152018/2015/lei/l13105.htm. Acesso em: 13 jul. 2020.

BRASIL. Lei $\mathbf{n}^{\circ} \mathbf{9 . 8 6 8}$, de 10 de novembro de 1999. Dispõe sobre o processo e julgamento da ação direta de inconstitucionalidade e da ação declaratória de constitucionalidade perante o Supremo Tribunal Federal. Disponível em:

http://www.planalto.gov.br/ccivil_03/leis//9868.htm. Acesso em: 13 jul. 2020.

BRASIL. Superior Tribunal de Justiça. Recurso em Habeas Corpus $\mathbf{n}^{0}$ 97.876. Relator Ministro Luís Felipe Salomão, julgado em 05 junho 2018a. Disponível em: https://ww2.stj.jus.br/processo/pesquisa/?tipoPesquisa=tipoPesquisaNumeroRegistro \&termo=201801040236\&totalRegistrosPorPagina=40\&aplicacao=processos.ea. Acesso em: 25 fev. 2020.

BRASIL. Superior Tribunal de Justiça. Recurso Especial n 1.782.418. Relator Ministra Nancy Andrighi, julgado em 3 de dezembro de 2018b. Disponível em: https://stj.jusbrasil.com.br/jurisprudencia/713190274/recurso-especial-resp-1782418rj-2018-0313595-7. Acesso em 25 fev, 2020.

BRASIL. Superior Tribunal de Justiça. Recurso Especial $\mathbf{n}^{\circ}$ 1.788.950. Relator Ministra Nancy Andrighi, julgado em 26 de abril de 2019. Disponível em: https://ww2.stj.jus.br/processo/pesquisa/?termo=1.788.950\&aplicacao=processos.ea \&tipoPesquisa=tipoPesquisaGenerica\&chkordem=DESC\&chkMorto=MORTO . Acesso em 25 fev, 2020.

BRASIL. Superior Tribunal de Justiça. Habeas Corpus $n^{0}$ 558.313/SP, Relator Ministro Paulo De Tarso Sanseverino, Terceira Turma, julgado em 23 de junho de 2020. Disponível em: https://ww2.stj.jus.br/processo/pesquisa/?tipoPesquisa= tipoPesquisaNumeroRegistro\&termo $=202000147655$ \&totalRegistrosPorPagina $=40$ \& aplicacao=processos.ea. Acesso em: 22 ago 2020.

BRASIL. Supremo Tribunal Federal. Ação Direta de Inconstitucionalidade $\mathbf{n}^{\circ}$ 5941. Relator Ministro Luiz Fux, medida liminar julgada em 17 maio de 2018c. Disponível em: http://portal.stf.jus.br/processos/detalhe.asp?incidente $=5458217$. Acesso em: 25 fev. 2020.

CÂMARA, Alexandre Freitas. O novo processo civil brasileiro. 4. ed. rev. atual. São Paulo: Atlas, 2018. 
CONSELHO NACIONAL DE JUSTIÇA. Portal CNJ. Sistemas de Pesquisa de Patrimônio. Disponível em: https://www.cnj.jus.br/sistemas/bacenjud/. Acesso em: 25 fev. 2020.

DIDIER JUNIOR, Fredie; BRAGA. Paula Sarno; CUNHA, Leonardo Carneiro da. Diretrizes para a concretização das cláusulas gerais executivas dos arts. 139, IV, 297 e 536, § 1 , CPC. Revista de Processo. v. 267, p. 227 - 27, maio 2017.

DIDIER JUNIOR, Fredie et al. Curso de direito processual civil: execução. 7. ed. ver. atual. ampl. Salvador: Juspodivm, 2017.

ENUNCIADOS DO FÓRUM PERMANENTE DE PROCESSUALISTAS CIVIS. Carta de Recife/PE. 10 ed. Brasília: Juspodivm, 2019.

FARIAS, Edilsom Pereira de. Colisão de direitos: a honra, a intimidade, a vida privada e a imagem versus a liberdade de expressão e informação. 2. ed. Porto Alegre: Fabris, 2000.

GAJARDONI, Fernando da Fonseca et al. Execução e recursos: comentários ao CPC 2015. 2. ed. Rio de Janeiro: Forense; São Paulo: Método, 2018.

GONÇALVES, Marcus Vinicius Rios. Processo civil: teoria geral do processo. 12. ed. São Paulo: 2019.

JARDIM, Guilherme Tanger. Princípio da responsabilidade patrimonial. In:

DALL'ALBA, Felipe Camilo; JARDIM, Augusto Tanger. Primeiras linhas de direito processual civil: execução. Porto Alegre: Livraria do Advogado, 2018.

MARINONI, Luiz Guilherme; ARENHART, Sergio Cruz; MITIDIERO, Daniel. Novo Código de Processo Civil comentado. 3. ed. rev. atual. São Paulo: Revista dos Tribunais, 2017.

MINAS GERAIS. Tribunal de Justiça de Minas Gerais. Agravo de Instrumento 1.0324.02.004607-8/001, Relator Des. Maria das Graças Rocha Santos, $11^{\text {a }}$ Câmara Cível, julgamento em 12 de fevereiro de 2020, publicação da súmula em 12 fev. 2020.

NEVES, Daniel Amorim Assumpção. Manual de direito processual civil. 10. ed. Salvador: JusPodivm, 2018.

NEVES, Daniel Amorim Assumpção. Medidas executivas coercitivas atípicas na execução de obrigação de pagar quantia certa - art. 139, iv, do novo CPC. Revista de Processo, São Paulo, v. 265, p. 107 - 150, mar. 2017.

NÓBREGA, Guilherme Pupe da. Reflexões sobre a atipicidade das técnicas executivas e o artigo 139, IV, do CPC de 2015. Migalhas. Processo e procedimento. 11 ago. 2016. Disponível em: http://www.migalhas.com.br/ProcessoeProcedimento/ 106,Ml243746,21048-Reflexoes+sobre+a+atipicidade+das+tecnicas+ executivas+e+o+artigo+139. Acesso em: 22 abr. 2020. 
PRESIDENTE PRUDENTE. Processo n. 1008033-49.2015.8.26.0482. Juiz de Direito Sérgio Elorza Barbosa de Moraes, da $5^{\mathrm{a}}$ Vara Cível da Comarca de Presidente Prudente/SP. Data da publicação: 26 jun. 2020.

RODRIGUES, Marcelo Abelha. Manual de execução civil. 5. ed. rev. e atual. Rio de Janeiro: Forense, 2015.

SANTA CATARINA. Tribunal de Justiça. Agravo de Instrumento $n^{\circ} .5012100$ 58.2020.8.24.0000. Relator Desembargador Sérgio Izidoro Heil, da $4^{a}$ Câmara de Direito Comercial. Data da publicação: 4 ago. 2020.

SANTOS, Marcos André Couto. A efetividade das normas constitucionais: as normas programáticas e a crise constitucional. Revista Jus Navigandi, Teresina, a. 9, n. 204, 26 jan. 2004. Disponível em: https://jus.com.br/artigos/4731. Acesso em: 25 fev. 2020.

SCARPARO, Eduardo. Pressupostos da execução. In: DALL'ALBA, Felipe Camilo; JARDIM, Augusto Tanger. Primeiras linhas de direito processual civil: execução. Porto Alegre: Livraria do Advogado, 2018.

SILVA, José Afonso. Curso de direito constitucional positivo. 25. ed. São Paulo: Malheiros Editores, 2005.

SIMÕES NETO, Eduardo. Breve justificativa das cláusulas pétreas. Migalhas. Migalhas de Peso. 01 nov. 2006.

TARTUCE. Fernanda. O polêmico inciso IV do artigo 139 do CPC e suas difusas interpretações. Instituto brasileiro de direito de família. 31 ago. 2016. Disponível em: http://www.ibdfam.org.br/noticias/6096/O+pol\%C3\%AAmico+inciso+ IV+do+artigo+139+do+CPC+e+suas+difusas+interpreta\%C3\%A7\%C3\%B5es\#>. Entrevista concedida ao Instituto Brasileiro de Direito de Família. Acesso em: 24 abr. 2020.

THEODORO JUNIOR, Humberto. Curso de direito processual civil. 50. ed. rev. atual. Rio de Janeiro: Forense, 2017. 3. v.

WAMBIER, Teresa Arruda Alvim et al. Primeiros comentários ao novo código de processo civil. São Paulo: Revista dos Tribunais, 2015.

ZAVASCKI, Teori Albino. Processo de execução: parte geral. 3. ed. rev., atual. e ampl. São Paulo: Revista dos Tribunais, 2004.

Artigo recebido em: 17/09/2020

Artigo aceito em: 03/12/2020

Artigo publicado em: 27/04/2021 